\title{
Riding the Wave of Belt and Road Initiative in Servitization: Lessons from China
}

\begin{abstract}
In light of increasing demand in services, manufacturers are moving further downstream in order to interact and respond to customers' needs more effectively. Several authors have proposed servitization models based on the product service system (PSS) concept. However, little is available to guide manufacturers to integrate their products and services in practice. Existing models tend to be vague in their implementation details, and the successful examples provided are mainly based on the multinational firms in developed countries. This paper aims to address the manufacturing servitization gap both in the literature and practice. This paper proposes a CIT (Customer Cocreation; Strategic Intent; Technology Mapping) framework to guide Chinese manufacturers to tap into the service value chain. The developed framework is then tested in a firm. This paper discusses the feasibility and practical implications of the proposed framework, and the wider implications for servitization under the belt and road initiative.
\end{abstract}

Keywords: Chinese Manufacturing, Servitization, Product Service System, Co-creation, Service Innovation, Belt and Road Initiative.

\section{INTRODUCTION}

As a consequence of increasing demand in services from customers (Oliva and Kallenberg, 2003), manufacturers are moving further downstream to interact with their clients in order to respond to their needs more effectively (Wise and Baumgartner, 1999). Services, which are intangible and invisible, bring benefits such as the difficulty to imitate, higher revenue, and sustainability in business (Heskett et al., 1997; Knecht et al., 1993; Potts, 1988; Quinn, 1992). Thus, the integrated product and service known as a product service system (PSS) lays the foundation of servitization concept which postulates that value can be added to an existing physical core product by offering additional services (Wuest et al. 2015).

Servitization can provide manufacturers with several advantages. By offering products and services that satisfy customers (high quality, unique, exceed expectation), manufacturers will be more attractive to existing and potential customers (Chung and Tan, 2017). Moreover, manufacturers can secure existing customers (customer loyalty) through service contracts. The "Power by the Hour" from Roll-Royce (Chang et al., 2014; Howells, 2000) is a well-known servitization example widely cited in literature and practice. More importantly, servitization provides manufacturers the benefits of: a) design and offer unique services/products to differentiate from competitors; b) sustainable business model; and c) better usage of resources and extend the product life cycle (Baines et al., 2007; Baines and Lightfoot, 2013). 
Baines et al., (2009) pointed out that there are more than 140 papers published with direct and indirect relation to the concept of servitization. There are some successful existing cases (Rolls Royces, Nespresso, Gillett, Xerox) in applying this concept, however many manufacturers stumble across great huddles as they struggle to change their business model from product to service-oriented, or transitional to relationship-based (Oliva, 2003). Firms need to perform extra services besides its core competencies which could have resulted in the demand of new additional capabilities, cultural-structural changes, and improvement in effectiveness and efficiency of operations (Durugbo, 2014).

To adopt the servitization strategy is a great challenge for Chinese firms because it requires fundamental transformation such as setting up new strategies, designing new offers (products and services) and processes, restructuring organisation and supply chain, introducing new support technology, and implementing the strategy in the front office (Brax, 2005; Baines et al, 2009; Oliva and Kallenberg, 2003; Slack, 2005). Obviously, for many Chinese firms where traditionally their main strength is commodity production, sudden changes in strategy such as adding a service element or customer engagement into a core product is a difficult task which can impact all aspects of an entire manufacturing operation. China has been dubbed as 'The World's Factory' since 1990s. Today, China is determined to move beyond the exporting of manufacturing goods. China's manufacturing capabilities and Chinese value chains have become increasingly sophisticated and globalised. In addition, it is estimated there are 550 million China's middle-class consumers in 2025 (Iskyan, 2016), bigger than the entire US population. Middle-class consumers have special appetite for foreign goods and are increasingly opting for online shopping to purchase medium-end to high-end products as it offers convenience as well as door-to-door delivery (Wong, 2017). Their consumption spending can reshape global trade and necessitate massive changes in service innovation and operations.

The 'Belt and Road Initiative' (BRI) commonly known as One Belt, One Road in public is a large China initiative to better integrate China rising economy and huge middle-class markets with the world. Hence, the drive for servitization is also more urgent for Chinese manufacturers. However, not all the manufacturers welcome this idea as they considered that it is beyond the scope of their strengths and resisted the change. The lack of knowledge to develop effective service resulted in the failure to execute servitization or dissatisfying outcomes (Kuijken, 2016; Oliva and Kallenberg, 2003; Tukker, 2015).

Based on a systematic literature review of servitization, Baines et al., (2017) pointed out a lack of papers in prescribing how to servitize manufacturing firms. Clearly, the information and guidances on servitization provided by existing literature is inadequate (Baines et al., 2017; Schenkl et al. 2014; Benedettini et al. 2015; Valtakoski, 2017). And this is where managers begin to feel uncomfortable. They ask: I want to integrate products and services, how can I do it? Firms are different, and the nature of the problems they experience varies according to sector, size and age, rate of growth, and the level of technology and innovation. In light of this, general servitization models can be less suitable for a specific firm (Schenkl et al. 2014).

Thus, managers need a structured framework to achieve servitization, they need implementation processes to be explained in a meaningful format i.e. how to engage 
customers in developing a sustainable service solution, what capabilities needed to do so, and the technology required to support the changes. Tan and Platts (2003) point out that appropriate visual representations can facilitate problem solving and discovery by providing an efficient structure for expressing information. By being able to visualise the range of servitization options and the operations capabilities that entails, managers are able to consider and give a fair appraisal of their merits. Then, the other challenge is "Would it be possible to build a process to enable managers to explore viable service models for their products?"

This paper reports on the on-going research work to address these questions by developing a structured framework to guide managers in rolling out servitization. In the first part of the paper, we explain how a framework is developed based on the customer co-creation, strategic intent, and technology mapping concepts. In part two, we describe the application of the framework in a real case and the results. Finally, we discuss how this research contributes to existing body of knowledge and its implications for practitioners.

\section{SERVITIZATION FRAMEWORK}

The concept of servitization was introduced in the late 1980s when Vandermerwe and Rada (1988) emphasised the importance of service as a way to add value to firms' core corporate offerings. Based on the belief that values are driven by customers, servitization offers an opportunity for manufacturers to sell more products by adding services to satisfy buyers' needs. Over the past 30 years, many researchers (Baines et al., 2009; Schenkl et al., 2014; Vasantha et al., 2013; Kuije et al., 2016; Wiesne et al., 2018) have proposed various conceptual frameworks to enable researchers and practitioners to better understand the servitization processes and challenges. To identify the popular conceptual frameworks for servitization, the authors used the Publish or Perish software (Harzing, 2007) which is hinged on Google Scholar's database to rank the most cited papers using the keyword "servitization". Based on the top 100 cited papers, the authors then identified those that proposed servitization frameworks and categorised them based on the characteristics of the underlying concepts. We conducted this review to better understand and familiar with the early principles and concepts of servitization research. The aim was not to identify the most cited servitization papers, but to identify a range of servitization frameworks that have the similar underlying characteristics. The findings revealed five categories of servitization frameworks and product service systems (see Table 1). 


\begin{tabular}{|l|l|l|}
\hline $\begin{array}{l}\text { Servitisation } \\
\text { frameworks }\end{array}$ & \multicolumn{1}{|c|}{ Characteristics } & References \\
\hline $\begin{array}{l}\text { Capability- } \\
\text { based }\end{array}$ & $\begin{array}{l}\text { Focus on identifying the gap between current status of product, } \\
\text { service offering, and customer needs before creating a new or re- } \\
\text { designed product and service-integrated solution. }\end{array}$ & $\begin{array}{l}\text { Vasantha } \\
\text { et al. 2013; } \\
\text { Coreynen } \\
\text { et al. 2018 }\end{array}$ \\
\hline Value-based & $\begin{array}{l}\text { A product-service 2 } \times 2 \text { matrix is used to represent the continuous } \\
\text { degrees of tangibility and interaction. The primary principle is that } \\
\text { "product and services differ with regard to the value that is created by } \\
\text { the tangible elements and the interaction moments between } \\
\text { manufacturers and customers". }\end{array}$ & $\begin{array}{l}\text { Kuije et al. } \\
2016\end{array}$ \\
\hline $\begin{array}{l}\text { Technology- } \\
\text { centred }\end{array}$ & $\begin{array}{l}\text { Emphasizing that integrated system technology is a major drive force } \\
\text { for PSS or an enabler of PSS from the technology-push and market- } \\
\text { pull concepts. }\end{array}$ & $\begin{array}{l}\text { Schenkl et } \\
\text { al. 2014 }\end{array}$ \\
\hline $\begin{array}{l}\text { Customer- } \\
\text { oriented }\end{array}$ & $\begin{array}{l}\text { Proposing an interlinked three layer models i.e. customer layer, } \\
\text { barrier layer, and solution layer. The key is to reduce customer } \\
\text { barriers and gain more customer acceptance. }\end{array}$ & $\begin{array}{l}\text { Schmidt et } \\
\text { al. 2015; } \\
\text { Shimomura } \\
\text { et al. 2018 }\end{array}$ \\
\hline $\begin{array}{l}\text { Production- } \\
\text { centric }\end{array}$ & $\begin{array}{l}\text { A framework to enable managers to consider the scope of service } \\
\text { delivery system, characteristic of value to be offered, and the } \\
\text { structural and infrastructural of operation decisions. }\end{array}$ & $\begin{array}{l}\text { Baines et } \\
\text { al. 2009; } \\
\text { Wiesne et } \\
\text { al. 2018 }\end{array}$ \\
\hline
\end{tabular}

\section{Table 1: Comparison of Servitization Frameworks}

The general purpose frameworks described above are useful to provide managers an overview of concepts and barriers to be considered in considering productservice integration. They provide a way of scoping the challenges and identifying relevant issues. However, because they are general purpose, they are not necessarily optimized for the servitization planning task. For example, value-based framework might result in overly complex solutions since it allows the development of multiple service values, whereas customer-oriented, useful for specific customers with clear boundaries, might be too simplistic and lack details on how to identify the required capabilities and technologies. Hence, it is clear that a visual and structured process is needed to assist managers in approaching servitization deployment.

Further scrutiny revealed that the five common frameworks could be further grouped together based on their main characteristics. The customer-oriented and valuebased frameworks are underpinned by the 'customer co-creation' concept. Whereas the capability-based and production centric frameworks share the similar 'strategic intent' underpinning. The technology-centred framework emphasizing on technology mapping. The grouping is not mutual exclusive, and there are some overlapping on the three concepts. Figure 1 shows a servitization framework that draws on the three key concepts (Customer co-creation, strategic intent, technology mapping). 


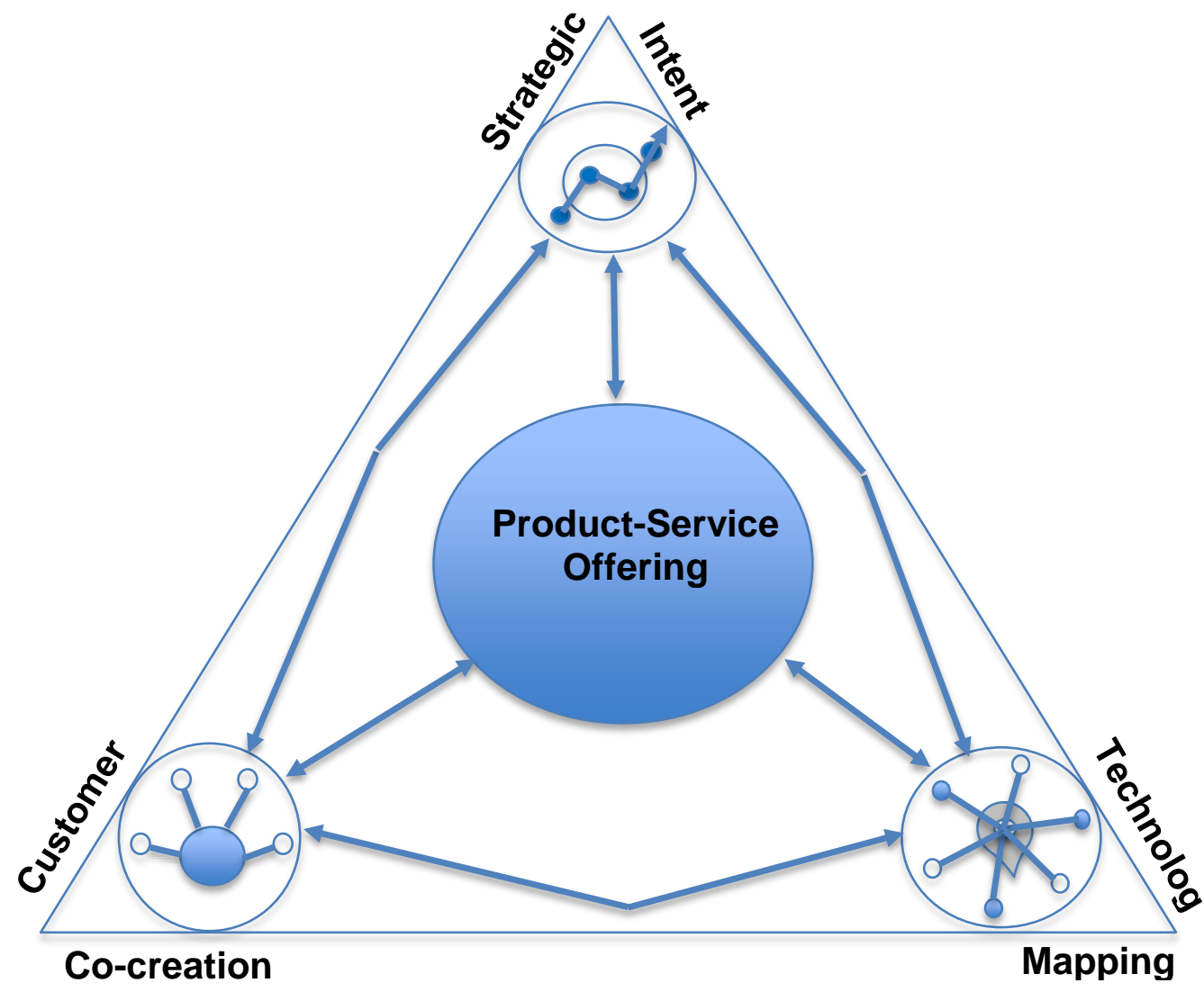

Figure 1: CIT Servitisation Framework

\subsection{Customer co-creation}

Tan et al. (2015) recently investigated how certain firms are able to determine their customers' needs and then innovate to meet those needs. Such companies are considered to be much more profitable than others (Cooper and Kleinschmidt, 2011; Wong, 2012). These firms are able to merge their ambitions and key abilities with their customers. Accordingly, a strong market orientation and the capability of managers to acquire customer needs are perceived as significant steps in development of new services (IBM, 2013; Steinfeld and Beltoft, 2014; Chuang and Lin, 2015). Clearly, customer co-creation should be a key step in the servitization process.

To develop a viable product-service offering, manufacturers must align service innovations with their manufacturing capabilities and competencies. Thus, they need to tap on supply chain partners' knowledge and resources as well as a variety of external stakeholders (Craighead et al. 2009). Moreover, customers can share information as well as further insights about their needs and requirements. Thus, manufacturers should engage actively with customers to gain better understanding of the product-service offerings. In other words, customers can become the "coproducers" by contributing essential knowledge, so that the manufacturers can 
develop new solutions to fulfil their needs (Zhang and Chen, 2008). Zhang et al. (2016) point out that manufacturers usually co-creates solutions, especially the intangible services with customers. In literature, co-creation is defined as customers directly participate in the design, development and delivery of customized solutions by applying their specialized knowledge and skills and through information sharing and joint production (Zhan et al. 2017). Customer involvement has been regularly advocated by management researchers as an approach to stiffening the feedback loop between expenditure and production cycles (Urban and Hauser, 2004). Among such perceptions is the assumption that customers are important sources of information and knowledge (Zhan et al. 2017), and it is acknowledged that customer involvement can improve service innovation (Tan and Zhan, 2016). Figure 2 shows the key elements of customer o-creation in servitization.

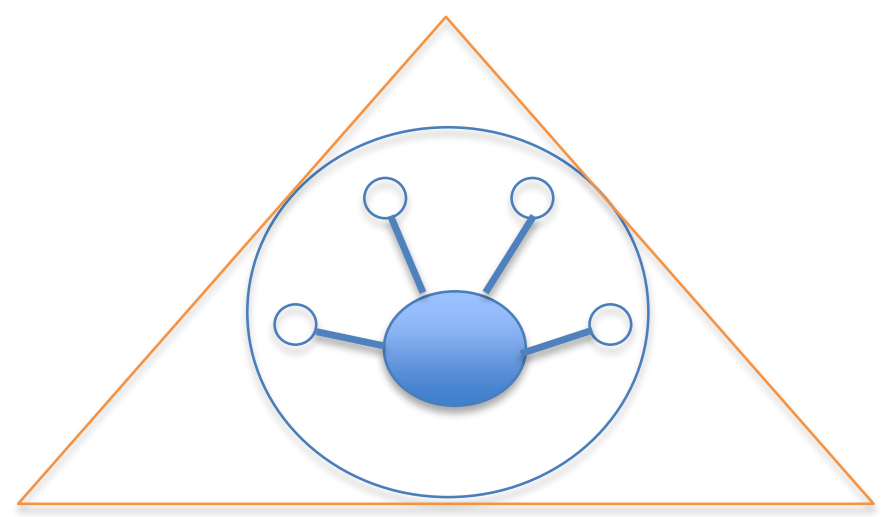

- Frequent interaction and knowledge exchange with customers

- Blends customers' unique experiences and ideas into new solutions

Figure 2: Customer Co-creation

\subsection{Strategic Intent}

Under BRI, China manufacturing eminence will be expanded beyond the middle kingdom, and at the same time be tested. To take on more sophisticated consumers, coping with macroeconomic realities in the new regions, and rising labour costs in China mean that the traditional approaches to manufacturing supply chain may no longer good enough (Eloot et al., 2013). Be it SMEs, SOEs or JVs, those that can tame supply chain complexity, capture supply chain innovation prowess, lower manufacturing costs, refine distribution channels will have a leading competitive edge to ride the $\mathrm{BRI}$ development. Hence, strategic intent will play a key role in transforming from manufacturing to services.

Strategic intent emphasizes manufacturers to extend their product-service offerings by building on their existing competences. Instead of managing fit between existing resources and current opportunities, managers need to be more innovative in making use of their limited resources. They must challenge the organisation and create misfit between resources and ambitions (Prahalad and Hamel, 1990). Prahalad (1998) points out that the goal is not to find a niche within the existing industry space but to create new space that is uniquely suited to the company's own strengths-space that is off the map. 
Clearly, the long term impact of BRI on the China/global manufacturing is immense. With such a variety of developments influencing businesses, firms need to explore whether the BRI and combined effects of the emerging trends are making a radical change in global supply chain configuration and how businesses best to adapt to these changes, as well as new service opportunities to offer. There will be a fundamental shift in characteristics of Chinese manufacturing under BRI, especially on how businesses setup their manufacturing facilities, provide integrated product/service solutions and configure their supply networks and distribution channels.

To ride the wave of BRI, firms need to carefully reconfigure their current regional footprint. Plant location requires medium and long term planning, resources, and attention - hence- a big impact on businesses' supply chain, business strategy, distribution channels, servitization, and bottom line (Tonby et al. 2014). Thus, firms not just need to ensure that their current plants and suppliers are agile, but also have the capability to reconfigure their existing supply network and response to changes rapidly when needed. Serving vast markets needs a sound production planning and capable to cope with sudden changes in the international market. They need to decide the order penetration points for various products and configure the supply network and infrastructure accordingly in order to better support their service operations. Figure 3 shows the key elements of strategic intent in servitization.

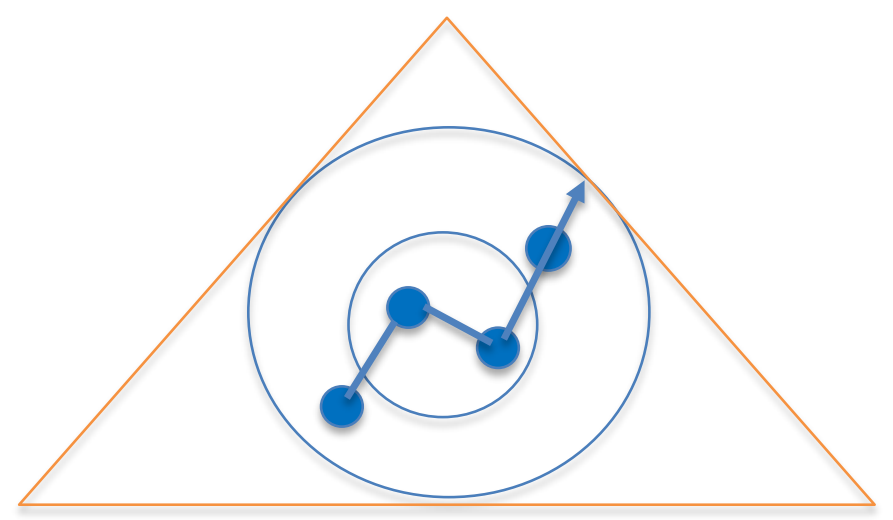

- Extends new offerings based on core competences

- Configures supply networks, distribution channels, and regional footprint

- Flexible business models for new markets and solutions

Figure 3: Strategic Intent

\subsection{Technology mapping}

Technology and big data is now changing how firms operate. Many researchers argue that there are many advantages that can be gained through technologies that harvesting big data, such as improved customer services, better operational efficiency, and ideas for new services and products (Wong, 2012). In particular, big data analytics has given rise to intelligent manufacturing and it can help to improve service operations in many ways. Retailers and manufacturers capture data all along their supply chains (Zhan \& Tan, 2017). It includes data collected from different sources such as: RFID tags, GPS locations, Member Card and Point of 
Sale (POS), data emitted by social media feeds and equipment sensors (Gandomi and Haider, 2015). For example, Walmart is an early adopter of technology driven supply chains informs its everyday decision making from sources across its whole supply chains - from automatic purchase to inventory tracking and customer fulfilment (Waller and Fawcett, 2013). Moreover, new technologies allow firms to achieve competitive advantage by improving effectiveness and efficiency, increasing the value-added services and producing higher-quality products (Coussement et al., 2015). Thus, to compete effectively in today's technology driven market place, manufacturers need to have a good understanding of their current and future technologies that should underpin their service operations.

The key issue managers need to address is the key resource technology to support their product-service offerings. New technologies and latest management trends ultimately challenges the current business norms. Servitization of manufacturing, cloud manufacturing, IoT, additive manufacturing, industry 4.0, new business models based on mass customization, and rising interests in sustainable and ethical supply chains (Song et al., 2018; Song and Wang, 2018) are creating exciting opportunities and challenges for manufacturers. Thus, manufacturers need to consider the wider industrial ecosystem to better meeting these challenges and embrace the new technologies to stay ahead of the game.

Under BRI, keeping track of customers at different regions is key to help manufacturers to prepare for supply chain uncertainties and better customised their services to meet local needs. Thus, manufacturers require better information gathering and analysis capabilities. As the marketplace (and supply chain) becomes increasingly fragmented, keeping better track of customer information and operations costs will be the main operations management challenges for manufacturers. Geum et al. 2011 point out three categories of technologies within PSS: a) "enabler technologies"- enable the direct integration of products and services. The technology may be independent or be part of (embedded into) the product; b) "mediator technologies" - existed in current products or service and are used for servitization; and c) "facilitator technologies" - added for facilitating product servitization. Given that technology is one of the key enablers for product-service offerings, it is important to understand its relevant aspects. Figure 4 shows the key elements of technology mapping in servitization. 


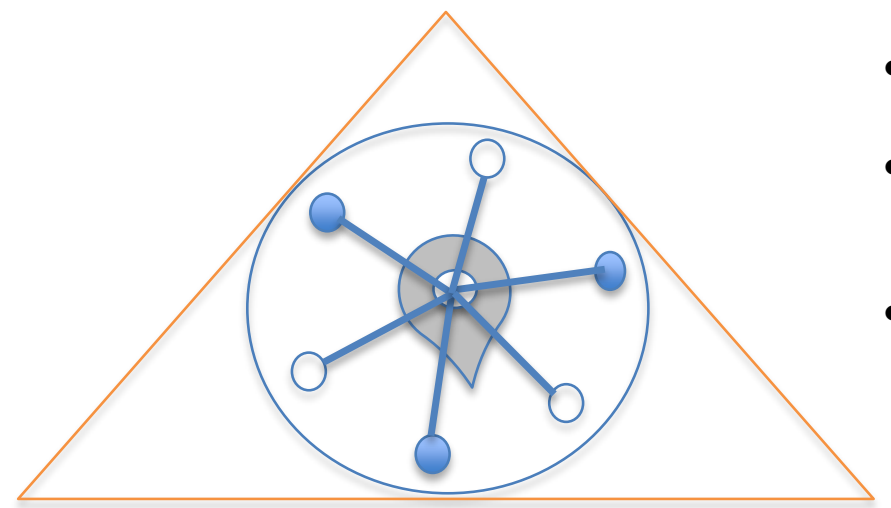

- Digital technologies enabled connectivity and real time interactivity

- Artificial intelligence (augmented reality) to enhance customers' experience

- Wider industrial ecosystem and network capabilities to access to knowledge, customers and resources

Figure 4: Technology Mapping

The proposed framework was developed based on the belief that the customer is the one who determines the value of the product (Ford, 1922). Thus, understanding the customer, enhancing capabilities, and utilising technology are the main principles underpinning the proposed framework. The goal of the framework is to provide guidance for managers to maximise customer satisfaction through servitization. The three principles will be integrated as a coherent set of tasks to guide managers through the servitization process. A workshop will be organised by the researchers to provide detail explanation to managers on how to apply the framework.

\section{CASE STUDY: A PRACTICAL APPLICATION}

This section discusses the application of the CIT framework in real industrial settings. In this study, we cooperated with one company (ChinaSuit) in the fashion/textile industry who are interested in applying the proposed framework to integrate product-service solutions to improve their current business performance. The case study was conducted using a process approach based on action research (Platts, 1994), with the researcher adopting the dual roles of 'facilitator' and 'observer.'

The case study was conducted at ChinaSuit, a leading suit maker in Wehnzhou, China. Its annual turnover is about 40 million USD. The main products are suit and custom tailoring suit mainly for North America and Western markets, and only tiny percentage is for domestic market. The name of the company has been changed to protect its identity. The study was centered at the corporate manufacturing office based in Wenzhou city. There are two main reasons ChinaSuit interested to take part in this research when approached by the researchers.

The main one being that ChinaSuit is producing for leading foreigner brands (OEM). The volume is good but the profit margin is very low. Thus, the management of ChinaSuit wanted to move away from OEM to OBM where it can command higher profit margin. Hence, the integration of product service solution for suit making to customer satisfaction is what the ChinaSuit management keen to get into. 
The other main reason is the rising labour wages, China suit makers are now facing competitions amongst competitors from countries with lower cost economies (i.e. India, Thailand, and Cambodia). Like many other Chinese manufacturers, ChinaSuit is facing several other challenges, one of the key ones being to improve business performance. Online shopping, social networking and mobile apps have been introduced recently to bring in more customers further afield. ChinaSuit management believes that "to add value by differentiating the product" is a potential solution to fend off competitions and establish long term competitive advantages. ChinaSuit considers servitization to be a sustainable strategy. Especially, they would like to engage customers earlier in the design process and extend their customisation capabilities. Moreover, ChinaSuit wants to ride the wave of BRI and expand their market globally.

Thus, ChinaSuit experimented with an integrated suit solution a while ago. However, it faced many challenges i.e. a) most of the branded design suits are not suitable for domestic customers due to different oriental and western body sizes; and b) the total suit solution package was not well accepted by domestic customers as they felt that ChinaSuit is pushing them a product and not a service solution. Hence, the management of ChinaSuit is keen to learn new approaches to product servitization. Given the international experience, competence and capabilities to supply suits for leading international brands, ChinaSuit management do not understand why their servitization initiatives was not successful.

The case study to test the framework was carried out with a team of managers and supported by researchers. Before commencing the case, a briefing was provided to the team members at which the researchers outlined the framework, identified the focused objective, and discussed the project aims. The workshop was conducted in Mandarin. Up-to-date written materials and reports about their operations were collected prior (and after) the workshop. Managers were asked to provide data to support their opinions or arguments where appropriate. Hence, the data was drawn from multiple levels and various perspectives.

In the initial stage of the workshop, we let the managers explained the company's process transition from manufacturing to servitization and their perception of the shift from products to service solutions. The second stage focused on how ChinaSuit can achieve a successful transition to servitization by following the key principles: customer co-creation; strategic intent; and technology mapping in the CIT framework. The framework provides crucial elements for establishing capabilities toward servitization. Moreover, we also explore the challenge of cultural issues in the servitization journey.

\section{RESEARCH FINDINGS}

The proposed framework requires detailed information about their current customers as well as potential future customer base. The key step of customer cocreation is to have interactive exchange with customers, hence, a good understanding of customers in various markets is crucial. It was a huge challenge for ChinaSuit who mainly has a database of current customers (leading western brand owners) and communication channels. Thus, it is not a straight forward 
process as the management needs to build a database of domestic customers who are likely to buy into the suit servitization package. One of the managers commented "it is not easy to gather a lot of customer information or setting up a big database due to the privacy issues and recent data protection rules".

During the discussion on how to better engage and understanding customers, one of the managers argued that retaining existing customers should be the priority as it is more profitable for ChinaSuit than finding new ones. A good personalised service (solution) can help to increase the future return purchase from existing customers. Moreover, existing customers have good relationships with ChinaSuit and can provide detailed information and ideas for new solution development. However, to provide better services to customers, ChinaSuit needs to know as much as possible about their customers i.e. personalisation is based on customers' personal information. One of the managers pointed out the challenge of balancing the act of providing personalised services that do not affect customers' privacy.

In light of the rising internet accessibility, ChinaSuit's managers highlighted the important of integrating customers as part of the value chain for service solutions development. China economy growth is supported by increasing medium-income population and high purchasing power. One of the managers commented that the demand for fast fashion is increasing rapidly, there is a shift from need-based purchase to aspiration purchase in the current new generation". Hence, the CIT framework enables managers to better understand the importance of closely integrating customers into their value chain.

ChinaSuit's managers pointed out that servitization is their strategy to extend new offerings based on current core competences to sustain competitive advantages in the market place. One of the managers pointed out that environmental and social compliances are not optional and sustainable manufacturing is key to underpin the servitization strategy under the BRI. Hence, in leveraging foreign partner/distributor competences, the environmental and social compliances should not be compromised.

The CIT framework also highlighted one of the main weaknesses of ChinaSuit i.e. the technology to provide the right market intelligent i.e. fashion trend, consumer behaviour (emphasis on fitness, increase women workforce) and demand for new fibres. One of the managers pointed that 'with rising income, Chinese consumers are more demanding and polyester is the popular choice of fibres for fast fashion. In short, the market is shifting fast and what technologies should we use to keep us staying on top of the market trends?" ChinaSuit managers agreed that market intelligence could serve as inputs for better decision making such as entering new market, developing new solutions or services around customer needs, as well as to develop strategies to cope with trade-blocks etc. From the discussion, managers in ChinaSuit also identified the need to integrate apps and websites to better entice customers for repeat businesses through better experience and services. One of the managers commented that "the CIT framework helps ChinaSuit to better understand servitization i.e. a process to continuously innovate new services and values with its products. ChinaSuit should see servitization as a strategic approach and a fundamentally change from good producing to offering a combination of goods 
and services as added value packages to customers in China specifically, and in BRI regions generally." Figure 5 shows some of the issues explored using CIT framework in the workshop.

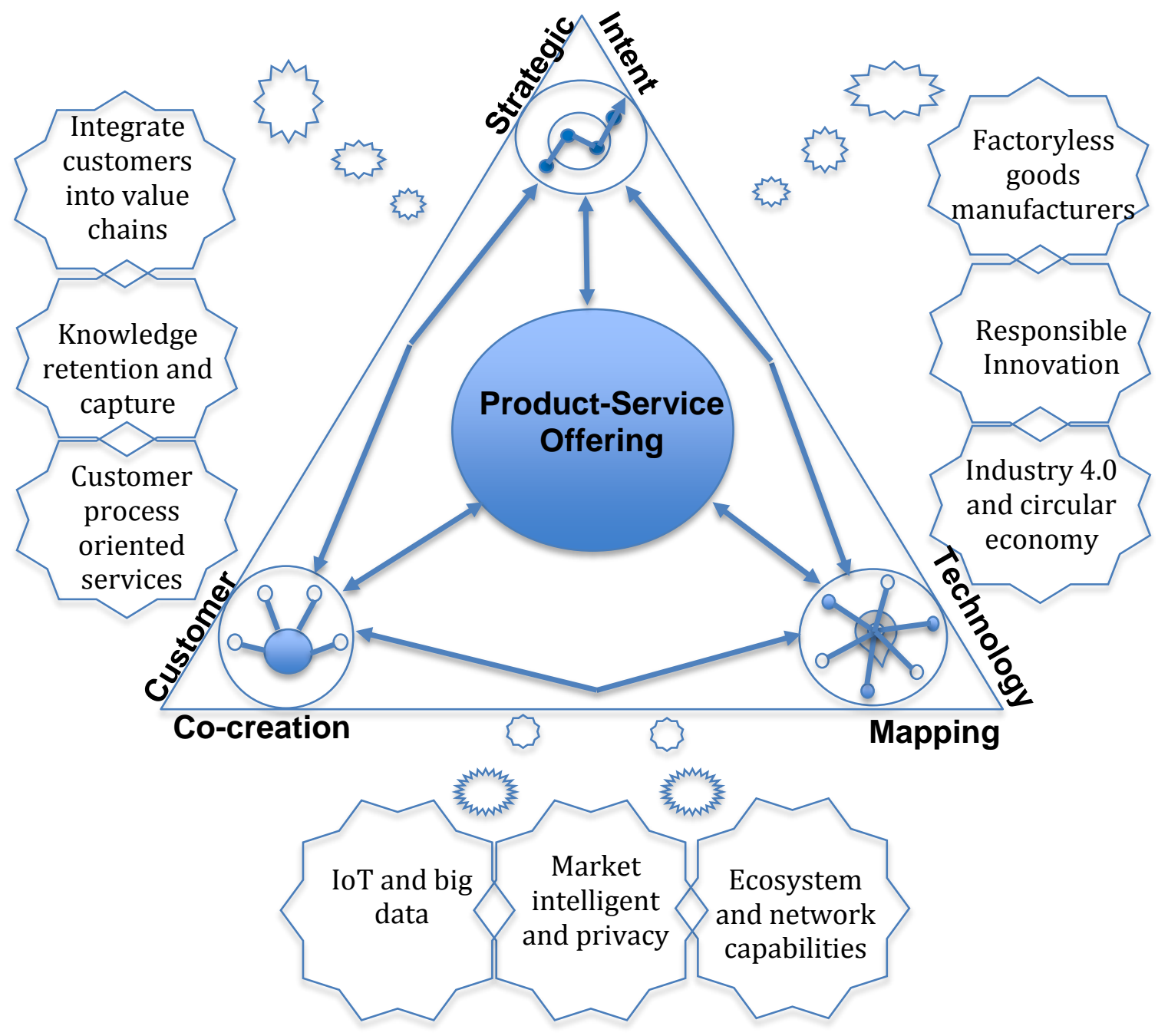

Figure 5: ChinaSuit Servitisation Triangle 
Overall, managers in ChinaSuit indicated the CIT framework is valuable but it is a time consuming process that involved in-depth analysis. The framework enables them to better understand servitization process and the interplay of customer, technology and strategy. We found that servitization will bring structural and cultural changes (Brax, 2005; Oliva and Kallenberg, 2003) to ChinaSuit. To apply the servitization concept, their business strategies and goals need to be adjusted as the "service" component is added to the existing product. ChinaSuit has to improve its operational process, introduce new technology and prepare staff to support the implementation of servitization (the transition from product-led to service-led strategy).

ChinaSuit is likely to have the capability to apply the framework to completion because of their existing capabilities and sufficient human resources. Another factor might be the opportunity to interact with customers. ChinaSuit owns a few stores in high streets, thus can interact with customers as well as provide services more easily.

The case results showed that servitization strategy brings complexities to firms and have an impact on structure, process, and culture within the operations. Effective information management and technology enhancement is key to servitization; the lack of technology can be an obstacle for the adoption of the concept. Lastly, servitization is a long-term strategy that requires continuous improvement in practice and regular performance monitoring. Servitization is a powerful strategy in the $21^{\text {st }}$ century to cope with rapid changes in customer needs and environment, yet it needs a well thought out plan and preparation as well as sophisticated infrastructure to support it.

The proposed CIT framework was evaluated based on the feasibility, usability and utility assessment criteria set out by Platts (1994) and Tan and Platts (2004). The feedback showed that the framework is appropriate and easy to follow. However, the framework has some limitations. Firstly, it requires a huge number of information for analysis such as customer demand \& market trends. Moreover, it may take a while for managers to go through the whole process as it involves a series of iterative loops of evaluation before viable services could be determined.

\section{DISCUSSION AND CONCLUSION}

The CIT servitization framework is developed based on three principles: customer co-creation, strategic intent, and technology mapping. Understanding and involving customers is key to servitization i.e. in determining the value of product and service. Understanding company's capabilities can provide crucial information to the development of new products, whilst utilising technology assists better effective and efficient resources employment.

The case feedback suggested that the proposed servitization model is timeconsuming and required substantial information regarding business context and customers. Overall, it demands manufacturers to shift the focus from the product to customers and service offerings which directly impact on the structure and culture of the business. Seemingly, the concept of servitization is straightforward and convincing, to put into practice firms manufacturers to be prepared to make changes in several operations strategy dimensions (structural, infrastructural, cultural). 
Although the underlying ideas of a visual framework is not new, their combination within a structured procedure provides a practical, usable and useful process for managerial decision making. Application of the process has provided a number of insights into aspects of servitization which add to academic understanding and could form the basis of further work. This section discusses the results of the work, and the wider implications for managers and academe. The findings are grouped and evaluated under two main areas: the value of a formal process; and the value of visualisation.

\subsection{The value of a formal process}

Far too frequently servitization implementation is carried out relatively informally. Manufacturers might spend significant time identifying produce-service ideas without a good understanding of servitization. This often occurs in an ad-hoc way based on the manager's past experience. Thus actions are often selected from a repertoire of existing solutions that managers are familiar with, whether appropriate or not. This is understandable, as faced with complexity, and the need to act, managers will tend to seek the comfort of the known (Tan and Platts, 2003). They will tend to redefine a problem to one which they had experienced before, where a tried solution exists. A formal framework and process provide a mechanism for mitigating this tendency. Our case results showed that managers liked the formality of the process. It gave them a sense of security. Although identifying suitable product-service solutions might be challenging, they felt reassured that an approach to addressing it was well followed and understood. A formal process helped managers to decompose the complexity of servitization into manageable steps. The value of team participation in the process was also demonstrated i.e. helped them to crystallise their thoughts and reduce inconsistencies at each step of the process.

\subsection{The value of visualisation}

Everyone makes decisions and acts based on reference to mental models that they have of the situation they are in. While this may suffice for individual decision making, it becomes problematic when transferred to an organisational context (Tan and Platts, 2003). Managers had different mental models of how their organisations operated, and might therefore make different opinions on the possible servitization strategies. There are clear benefits of developing a shared and agreed model of an organisation's operation. The framework allows managers to visualise the process, provided them with a way of formalising, capturing and sharing their mental models. Moreover, the process is educative, it encourages learning both at an individual and group level. By iterative modelling and group discussion, managers learn, modifying their understanding, ideas, beliefs and even their thought processes over time.

\subsection{Limitations and Future directions}

BRI brings new and exciting opportunities and uncertainties for manufacturers. However, to stay competitive will require manufacturers to change their business mind-sets and operations strategies. BRI will transform global supply chain for the better. Even though some of the discussed trends is still at the fringes of BRI, this 
paper offers a few insights for the future. Strategically, business structural and infrastructural flexibility (Tan and Platts, 2004; Brennan et al. 2015) across the supply chain is core to support competitive advantage.

We have demonstrated, how the CIT framework and process can facilitate the generation and communication of servitization. However, the cases were mainly based on manufacturers in China. Thus, a much wider application of the proposed CIT framework in other countries is needed to test its generalisabilities. Moreover, different industry will have different challenges in dealing with servitization. Thus, future research to test CIT framework in other industries such as electronics, automobiles, food etc. should be carried out. Besides servitization, future research can investigate what other alternative strategies are available for manufacturing firms to sustain competitive advantages.

\section{Acknowledgements}

The authors are thankful the participants of ICPR 2017 and anonymous reviewers for their constructive and helpful comments which helped to improve the argument flow of this paper considerably. This research was supported by the National

Natural Science Foundation of China (NSFC) (Project Nos. 71571151 and 71871197 and 71872158), and UK Royal Society International Exchanges 2015 Cost Share (China), IE150652.

\section{REFERENCES}

Baines, T., Lightfoot, H. W., Evans, S., Neely, A., Greenough, R., Peppard, J., Roy, R., Shehab,E., Braganza, A., Tiwari, A., Alcock, J. R., Angus, J. P., Bastl, M., Cousens, A., Irving R.,Johnson, M., Kingston, J., Lockett, H., Martinez, V., Michele, P., Tranfield, D., Walton, I. M.and Wilson, H. (2007). ' State-of-the-art in product-service systems', Journal of Engineering Manufacture, Part B: 1543-51.

Baines, T., Lightfoot, H., Peppard, J., Johnson, M., Tiwari, A., Shehab, E., Swink, M. (2009). 'Towards an operations strategy for product-centric servitization', International Journal of Operations \& Production Management 29(5): 494-519.

Baines, T. and Lightfoot, H.W. (2013). 'Servitization of the manufacturing firm', International Journal of Operations \& Production Management 34(1): 2-35.

Baines, T., Ziaee Bigdeli, A., Bustinza, O. F., Shi, V. G., Baldwin, J., \& Ridgway, K. (2017). Servitization: revisiting the state-of-the-art and research priorities. International Journal of Operations \& Production Management, 37(2), 256-278.

Benedettini, O., Neely, A., \& Swink, M. (2015). Why do servitized firms fail? A risk-based explanation. International Journal of Operations \& Production Management, 35(6), 946-979.

Brax, S. (2005). 'A manufacturer becoming service provider -challenges and a paradox', Manufacturing Service Quality 15(2): 142-56.

Chung, L.; Tan, K.H. (2017), "The unique Chinese Innovation Pathways: Lessons from Chinese Small and Medium Size Manufacturing Firms", International Journal of Production Economics, Vol 190, pp. 80-87.

Chuang, S.H. and Lin, H.N., 2015. Co-creating e-service innovations: Theory, practice, and impact on firm performance. International Journal of Information Management, 35(3), pp.277-291. 
Chang, Y. C., Miles, I. and Hung, S. C. (2014). 'Introduction to special issue: Managing technology-service convergence in Service Economy 3.0', Technovation 34(9): 499504.

Coussement, K., D. F. Benoit, M. Antioco. 2015. A Bayesian approach for incorporating expert opinions into decision support systems: A case study of online consumersatisfaction detection. Decision Support Systems. 79: 24-32.

Cooper, R. G. and Kleinschmidt, E. J. 2011. New products: the key factors in success, Marketing Classics Press, USA.

Coreynen, W., Matthyssens, P., De Rijck, R., \& Dewit, I. (2018). Internal levers for servitization: How product-oriented manufacturers can upscale product-service systems. International Journal of Production Research, 56(6), 2184-2198

Craighead,W., Hult,G.T.M. ,K.J.D.,J., (2009). The effects of innovation-cost strategy, Knowledge, and action in the supply chain on firm performance. Journal of Operation Management. 27(5), 405-421.

Durugbo, C. (2014). 'Strategic framework for industrial product-service co-design: findings from the microsystems industry', International Journal of Production Research 52(10): 2881-2900.

Eloot, K., Huang, A., \& Lehnich, M. (2013). A new era for manufacturing in China. McKinsey Quarterly, 1.

Ford, H. (1922). My Life and Work, Kessinger Publishing, Whitefish, MT.

Gandomi, A., M. Haider. 2015. Beyond the hype: Big data concepts, methods, and analytics, International Journal of Information Management. 35: 137-144.

Geum Y, Lee S, Kang D, Park Y. (2011) Technology Roadmapping for technology-based product - service integration: A case study. Journal of Engineering and Technology Management. 28:128-46.

Harzing, A.W. (2007). Publish or Perish, available from https://harzing.com/resources/publish-or-perish

Howells, J. (2000). 'Innovation and services: new conceptual frameworks', CRIC Discussion Paper 38, UMIST International Publication, Manchester

Heskett, J. L., Sasser, W. E. and Schlesinger, L. A. (1997). The Service Profit Chain, Free Press, New York, NY

IBM. 2013. What is big data? - Bringing big data to the enterprise. IBM, available at: www.IBM.com (accessed Mar 03, 2015).

Iskyan, K. (2016) "China's Middle Class is Exploding". Business Insider, Aug 28. Accessed on 13 Nov 2017. http://uk.businessinsider.com/chinas-middle-class-is-exploding2016-8? $\mathrm{r}=\mathrm{US} \& \mathrm{IR}=\mathrm{T}$

Knecht, T., Leszinski, R. and Webber, F. (1993). 'Memo to a CEO', The Mckinsey Quarterly 4: 79-86.

Kuijken, B., Gemser, G., Wijnberg, N. M. (2016). 'Effective product-service systems: A value-based framework', Industrial Marketing Management. http://www.sciencedirect.com/science/article/pii/S0019850116300724>

Oliva, R. and Kallenberg, R. (2003). 'Managing the transition from products to services', International Journal of Service Industry Management 14(2): 160-172.

Potts, G. W. (1988). 'Exploiting your product's service life cycle', Hardvard Business Review, 66(5): 32-35

Platts, K.W. (1994). 'Characteristics of Methodologies for Manufacturing Strategy', International Journal of Operations and Production Management 13(8): 4-17. 
Prahalad, C. and Hamel, G. (May-June, 1990). "The Core competence of the corporation". Harvard Business Review, pp.79-91.

Prahalad, C. (May/June 1998) . "Managing discontinuities:The Emerging challenges". Research Technology Management, 41(3), pp. 14-22.

Quinn, J. B. (1992). Intelligent Enterprise, Free Press, New York, NY.

Song, M., Wang, S., and Sun, J. (2018) Environmental regulations, staff quality, green technology, R\&D efficiency, and profit in manufacturing. Technological Forecasting \& Social Change, 133: 1-14.

Song, M. and Wang, S. (2018). Effects of outward migration of factory for the BeijingTianjin-Hebei city circle. International Journal of Computer Integrated Manufacturing, 31(6): 513-522.

Steinfeld, E. S., \& Beltoft, T. (2014). Innovation lessons from China. MIT Sloan Management Review, 55(4), 49-55.

Schenk1, S. A., Sauer, R. M. and Mortl, M. (2014). 'A Technology-centered Framework for Product-Service Systems', Procedia CIRP 16: 295-300.

Shimomura, Y., Nemoto, Y., Ishii, T., \& Nakamura, T. (2018). A method for identifying customer orientations and requirements for product-service systems design. International Journal of Production Research, 56(7), 2585-2595.

Slack, N., Lewis, M., Bates, H. (2004). 'The two worlds of operations management research and practice: Can they meet, should they meet?', International Journal of Operations and Production Management 24(4): 372-387.

Schmidt, D. M., Malaschewski, O., Fluhr, D., Mortl, M. (2015). 'Customer-oriented Framework for Product-Service Systems', Procedia CIRP 30: 287-292.

Tan, K. H., Zhan, Y., Ji, G., Ye, F. \& Chang, C. (2015). Harvesting big data to enhance supply chain innovation capabilities: An analytic infrastructure based on deduction graph. International Journal of Production Economics, 165, 223-233.

Tan, K.H.; Zhan, Y. (2016), "Improving New Product Development Using Big Data: A Case Study of an Electronics Company", $R$ and D Management, pp. 1-13.

Tan, K.; Platts, K. (2003)., "Linking Objects to Action Plans: A Decision Support Approach Based on the Connectance Concept", Decision Sciences, Vol.34 (3), pp.569-593.

Tan, K.; Platts, K.(2004)., "Operationalising Strategy: Mapping Manufacturing Variables", International Journal of Production Economics, Vol.89 (3), pp.379-393.

Tonby, O., Ng, J., \& Mancini, M. (2014). Understanding ASEAN: The manufacturing opportunity. Singapore: McKinsey \& Company.

Tukker, A. (2015). 'Product services for a resource-efficient and circular economy - A review', Journal of Cleaner Production 97: 76-91.

Urban, G. \& Hauser, J. R. (2004). Listening in to find and explore new combinations of customer needs. Journal of Marketing, 68(April), 72-87.

Vandermerwe, S. and Rada, J. (1988). 'Servitization of Business: Adding Value by Adding Srrvices', European Management Journal 6(4)

Vansantha, G. V. Annamalai., Komoto, Hitoshi., Hussain, Romana., Roy, Tomiyama, Tetsuio., Evans, Steve., Tiwari, Ashutosh. and Williams, Stewart. (2013). 'A manufacturing framework for capability-based product-service systems design', Journal of Remanufacturing 3(8)

Valtakoski, A. (2017). Explaining servitization failure and deservitization: A knowledgebased perspective. Industrial Marketing Management, 60, 138-150. 
Waller, M. A. S. E. Fawcett. 2013. Click here for a data scientist: Big data, predictive analytics, and theory development in the era of a maker movement supply chain, Journal of Business Logistics. 34(4): 249-252.

Wong, B. (2017). China's Middle-Class Consumers: Online Shopping Habits. HKTDC Research, 2 August 2017. http://economists-pick-research.hktdc.com/businessnews/article/Research-Articles/China-s-Middle-Class-Consumers-Online-ShoppingHabits/rp/en/1/1X000000/1X0AAU8A.htm Accessed on 28 September 2018.

Wiesner, S., \& Thoben, K. D. (2017). Requirements for models, methods and tools supporting servitization of products in manufacturing service ecosystems. International Journal of Computer Integrated Manufacturing, 30(1), 191-201.

Wise, R. and Baumgartner, P. (1999). 'Go downstream: the new profit imperative in manufacturing', Harvard Business Review 77(5): 133-141.

Wuest, T., Hribernik, K., \& Thoben, K.-D. (2015). Accessing servitization potential of PLM data by applying the product avatar concept. Production Planning \& Control, (May 2015), 1-21.

Wong, D. 2012. Data is the Next Frontier, Analytics the New Tool: Five trends in big data and analytics, and their implications for innovation and organisations. London: Big Innovation Centre.

Zhang,X.,Chen,R.,(2008).Examiningthemechanismofthevalueco-creationwith customers. International Journal of Production Economics. 116(2),242-250.

Zhang, M., Zhao, X., Voss, C., \& Zhu, G. (2016). Innovating through services, co-creation and supplier integration: Cases from China. International Journal of Production Economics, 171, 289-300.

Zhan, YZ., Tan,K.H., Tse, YK., Li, Y. (2017), "Unlocking the Power of Big Data in New Product Development", Annals of Operations Research, pp. 1-9. 